\title{
IMPORTÂNCIA DA AGILIDADE NO ATENDIMENTO AOS PACIENTES SUSPEITOS DE TUBERCULOSE PULMONAR EM UMA UNIDADE DE EMERGÊNCIA DE UM HOSPITAL MUNICIPAL DE SÃO PAULO
}

Eixo temático: Avaliação e Qualidade do Cuidado

\author{
Andrea Mayumi Loureiro Hayashi; Cristina Harumi Tozaki Oshima; Rafael Baptista Pardo; Solange Felomeno Caramello \\ Hypolito;Vanessa Cerávolo Gurgel Silva.
}

\begin{abstract}
INTRODUÇÃO
A tuberculose (TB) é uma doença infectocontagiosa causada pela bactéria denominada Mycobacterium tuberculosis, afeta principalmente o parênquima pulmonar e podem acometer outros órgãos do corpo (1). A principal fonte de infecção ocorre através da inalação de bacilos expelidos pela tosse e fala do doente bacilífero ${ }^{(1,2)}$. A TB é considerada como um importante agravo de saúde pública exigindo o desenvolvimento de estratégias para o seu controle pois sua prevalência ocorre em áreas de grande concentração populacional associados a condições socioeconômicas e sanitárias precárias $(1,2)$. Segundo o Ministério da Saúde, a busca ativa dos sintomáticos respiratórios, deve ser realizada em todos os serviços de saúde e constitui uma das principais estratégias para interromper a cadeia de transmissão(1).
\end{abstract}

\section{OBJETIVO}

Mostrar a importância do diagnóstico precoce da TB Pulmonar para redução da disseminação de bacilos através de atendimento eficaz e tratamento adequado.

\section{METODOLOGIA}

Realizado um levantamento do perfil epidemiológico, análise crítica e reflexiva, retrospectiva da estruturação do fluxo de atendimento ao paciente com suspeita de TB desde da entrada do paciente até sua alta, no Hospital Municipal Vereador José Storopolli de São Paulo no período de janeiro a dezembro de 2018.

Figura 1- Fluxo de atendimento de pacientes com suspeita de TB Pulmonar.

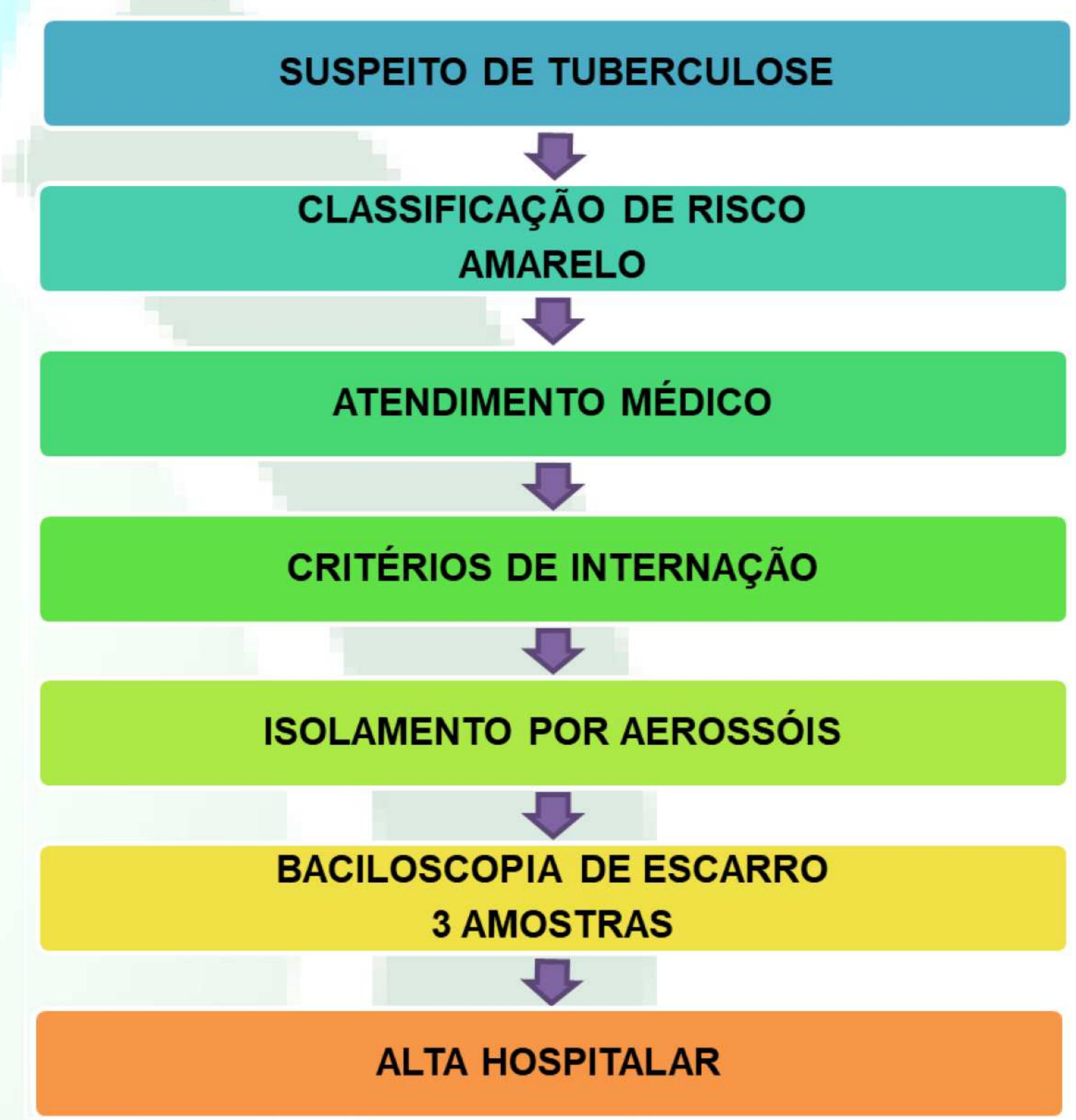

\section{RESULTADOS}

Foram analisados 102 casos de TB, sendo que 92 pacientes foram diagnosticados com TB Pulmonar, $57 \%$ dos casos de TB Pulmonar $(n=54)$ necessitaram de internação hospitalar e destes $70 \%(n=38)$ eram bacilíferos, $41 \%(n=38)$ dos casos foram diagnosticados no Pronto Atendimento e destes $89 \%(n=34)$ das baciloscopias positivas foram identificadas no mesmo dia do atendimento, sendo que apenas $11 \%(n=4)$, com baciloscopia negativa diagnosticados pelo método de PCR (Reação em Cadeia da Polimerase) ou cultura e levaram 32 dias em média para seu diagnóstico.

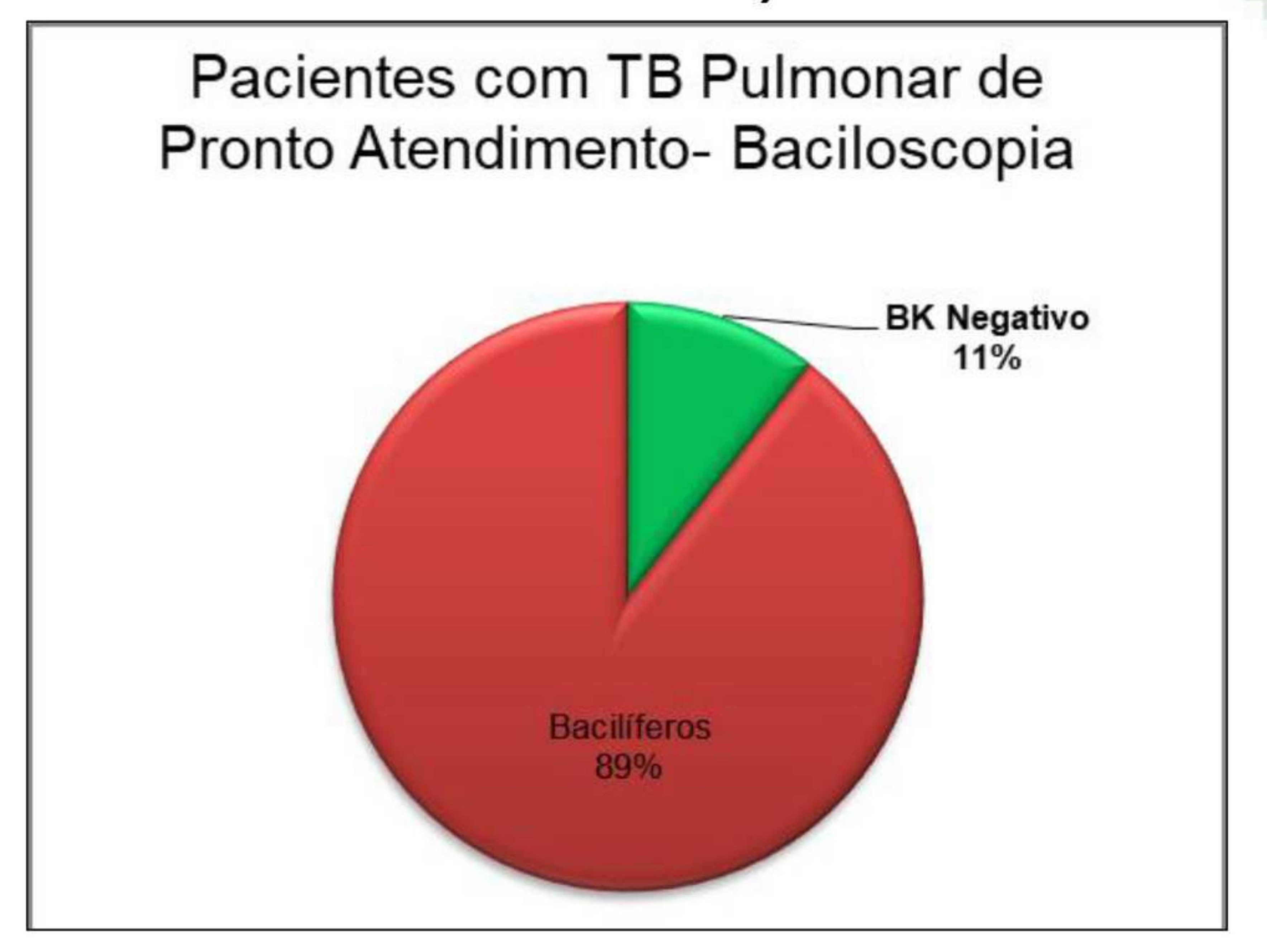

Figura 2- Distribuição de pacientes com TB Pulmonar de Pronto Atendimento, segundo resultado de baciloscopia

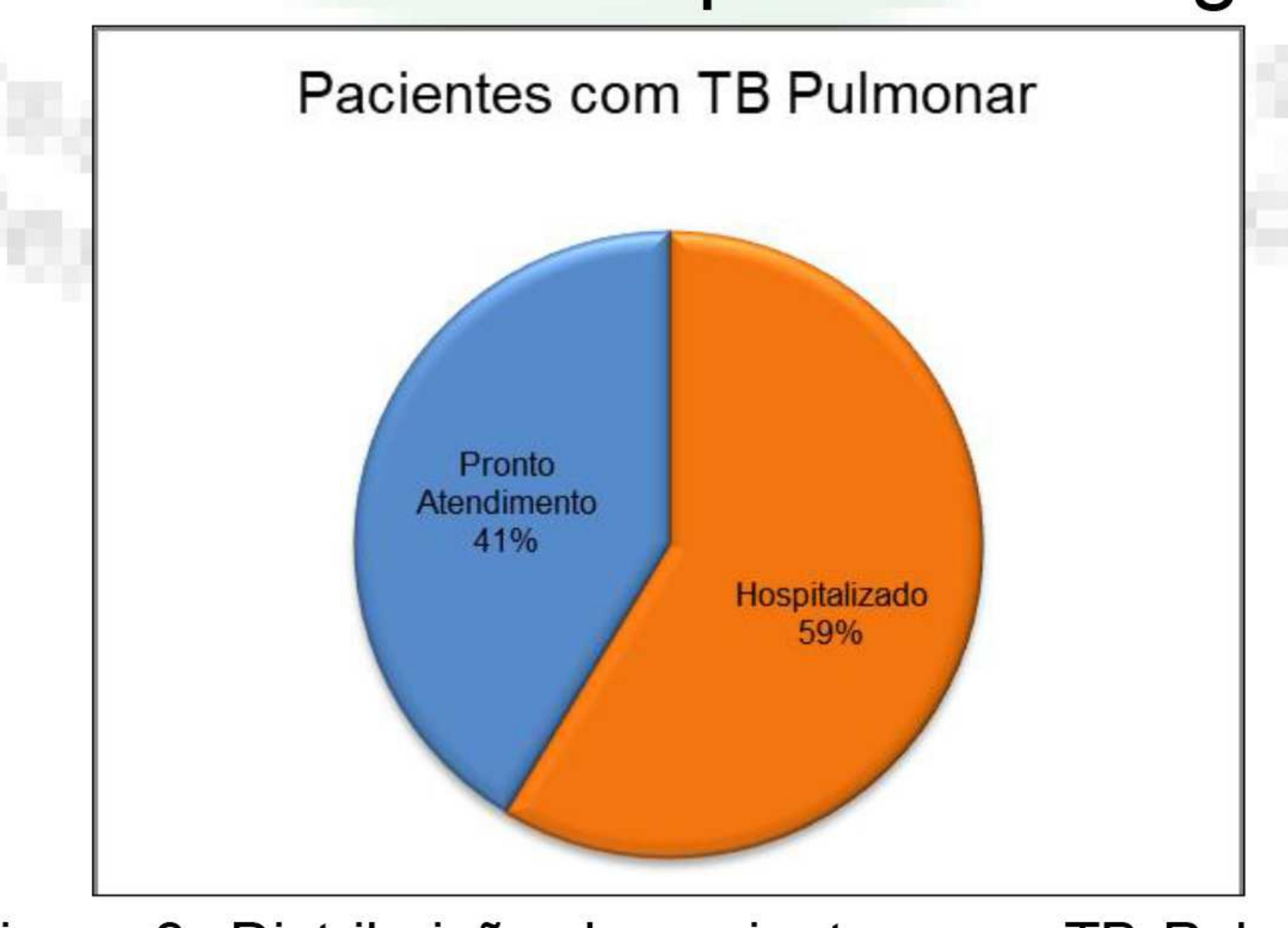

Figura 3- Distribuição de pacientes com TB Pulmonar, segundo necessidade de internação.

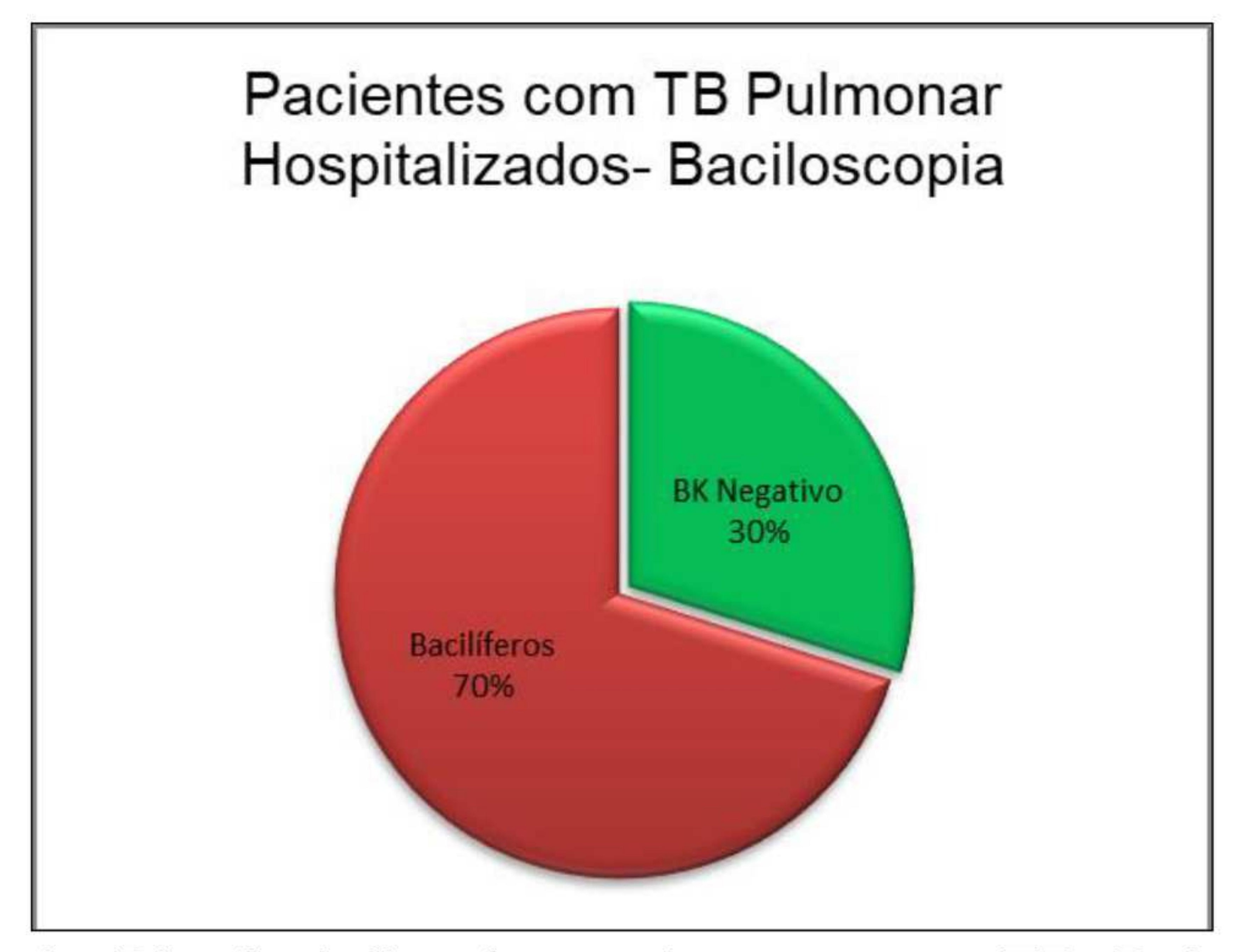

Figura 4- Distribuição de pacientes com TB Pulmonar hospitalizados, segundo resultado de baciloscopia.

\section{CONCLUSÃO}

A TB é um agravo á saúde de grande magnitude que necessita uma ampla atenção das organizações de saúde. Os serviços hospitalares devem atuar na agilidade do atendimento, diminuição dos riscos de transmissão da doença, diagnóstico precoce através da execução da baciloscopia de urgência, tratamento adequado e vigilância pós alta dos exames realizados durante a internação.

\section{REFERÊNCIAS}

1-BRASIL. Ministério da Saúde. Secretaria de Vigilância em Saúde. Manual de recomendações para o controle da tuberculose no Brasil /Secretaria de Vigilância em Saúde - Brasília : Ministério da Saúde, 2011.

2-FUNDAÇÃO NACIONAL DE SAÚDE. Normas para o controle da tuberculose. $5^{\text {a }}$ ed. Brasília: Ministério da Saúde; 2002. 